\title{
Examining interaction effects among land-use policies to reduce household vehicle travel: An exploratory analysis
}

\author{
Kwangyul Choi \\ School of Architecture, Planning and \\ Landscape \\ Haskayne School of Business \\ University of Calgary \\ kwangyul.choi1@ucalgary.ca
}

\author{
Robert Paterson \\ Community and Regional Planning, School \\ of Architecture \\ The University of Texas at Austin
}

\begin{abstract}
Numerous studies have suggested that land-use policies can reduce vehicle travel through mode shifting and reduced trip lengths and generation of fewer or more efficient trips. The findings from previous studies also suggest that the combined effect of two or more land-use policies can be significant, although the effects of individual policies appear to be modest. These studies present area-wide impacts of land-use policies on travel and suggest that their effects are additive. However, very little is known about how each land-use policy interacts with the others at different levels of development intensity to reduce vehicle travel. In this study, we explore how three well-known land-use strategies (densification, mixed-use development, and street network improvement) interact with each other by testing possible combinations of land-use factors and focus on how these interactive effects vary by the level of development intensity. Employing ordinary least squares regression analysis using a dataset created for the Austin metropolitan statistical area (MSA) (using 2006 Austin Travel Survey data), we examine the impact of land use on household vehicle travel. Our findings suggest that interaction effects occur, but they vary by development intensity. The results of this study show the importance of considering both threshold (development intensity) and interaction (combination of policies) effects in understanding how land-use factors do and do not affect travel (based on their interactive opposed to only their direct and additive effects). Though this paper uses data from just one MSA and thus is merely suggestive, it does point to a possibly more nuanced use of the commonly prescribed planning and design policy variable to account for variation in effectiveness based on differences in development intensity. For example, we find that greater land-use intensification has higher efficacy in changing vehicle travel behavior in areas with relatively higher development intensity. Future research should include data from a broader array of metropolitan areas and incorporate additional predictor variables that were unavailable for this analysis.
\end{abstract}

Keywords: Vehicle miles traveled (VMT), land-use policies, threshold effects, interaction effects, Austin

\section{Article history:}

Received: October 27, 2017

Received in revised form:

August 16, 2019

Accepted: October 4, 2019

Available online: November 15, 2019

Copyright 2019 Kwangyul Choi \& Robert Paterson

http://dx.doi.org/10.5198/jtlu.2019.1337

ISSN: 1938-7849 | Licensed under the Creative Commons Attribution - Noncommercial License 4.0

The Journal of Transport and Land Use is the official journal of the World Society for Transport and Land Use (WSTLUR) and is published and sponsored by the University of Minnesota Center for Transportation Studies. 


\section{Introduction}

Vehicle travel is known to have negative impacts on the environment: greenhouse gas emissions are just one example (Rawlins \& Paterson, 2009). A heavy reliance on automobiles is correlated with physical inactivity that worsens individual health and quality of life (Bauman et al., 2012). To reduce these impacts, various land-use strategies have been proposed by both planning scholars and practitioners, and over the past several decades, the relationship between land use and travel behavior, particularly vehicle miles traveled (VMT), has been intensively studied. A significant body of literature has demonstrated that land-use policies such as densification, mixed-use development, and street network improvement can reduce VMT and encourage travel by active modes of transportation and therefore help alleviate the negative impacts of auto-dominant travel (Stevens, 2017).

Though a number of studies have focused on the impacts of individual land-use policies and a few have addressed synergistic effects with other policies, particularly pricing (parking and road/toll), less effort has been made to examine interaction effects among land-use policies on travel behavior. Hence, in this paper, we explore how land-use policies interact in terms of reducing vehicle travel. We explore the following propositions with respect to daily household VMT in the Austin metropolitan area in Texas.

1. Land-use policies can have a significant effect on household VMT, but the effects can vary by the level of development intensity (threshold effects).

2. The effects of combined land-use policies may be not only additive but also marginalized, synergistic, or even opposites (interaction effects).

Specifically, this study attempts to fill the gap in the existing body of research by employing ordinary least squares (OLS) regressions with the interaction of three land-use policies (densification, mixed-use development, and street network improvement) at various levels of development intensity. We contribute to the growing body of literature on the land use and travel connections by extending the understanding of the interaction effects of land-use policies with the development intensity of a given neighborhood.

\section{$2 \quad$ Literature review}

During the past several decades, numerous studies on the relationship between land use and travel behavior have been conducted (Boarnet \& Crane, 2001; Brownstone \& Golob, 2009; Cervero \& Kockelman, 1997; Ewing, Hamidi, Gallivan, Nelson, \& Grace, 2014; Ewing \& Cervero, 2001, 2010; Wang, 2013). These studies have provided empirical evidence as well as comprehensive reviews of the existing literature on land use and travel connections and suggested that land-use intensification can reduce vehicle travel and encourage nonmotorized travel. These studies have reached a consensus that people living in compact, well-mixed neighborhoods with adequate transit service tend to drive less and travel more by walking, biking, or transit. However, these studies assumed that the effects of land-use policies are additive- that is, their influence on travel is cumulative, and no interactions occur between the effects of land-use policies. Another large body of existing literature has focused on travel mode choice (Cervero, 2002; Kenworthy, 2006; Pinjari, Pendyala, Bhat, \& Waddell, 2011; Zhang, 2004). These studies also concluded that residents of neighborhoods with a lower level of land-use intensity and scant public transit provision are likely to drive alone, whereas those from neighborhoods with higher land-use intensity and better access to other modes of transportation tend to use alternatives modes at higher rates.

Besides land use, travel behavior is influenced by several other factors, which makes it difficult for researchers to disentangle the relationship between land use and travel behavior. Among those factors, the self-selection effect, which refers to the fact that households may choose their residential location based on their travel preference, has obscured the directionality and causality between land use and travel 
(Bhat \& Guo, 2007; Mokhtarian \& Cao, 2008; Van Wee, 2009). Because the issue of self-selection primarily results from households' attitudes, lifestyles, or demographic/socioeconomic characteristics, researchers have attempted to solve self-selection problems through stronger research designs (Cao, Mokhtarian, \& Handy, 2009). In terms of data, studies with disaggregate data have found that the effects of self-selection can be controlled by including a rich set of socio-demographic characteristics of travelers (e.g., race/ethnicity, income, household size). With detailed and rich sociodemographic information, the connection between land use and travel can be jointly modeled to account for self-selection effects through various advanced statistical modeling techniques (Bhat, Astroza, Sidharthan, Alam, \& Khushefati, 2014; Brownstone \& Golob, 2009; de Abreu E Silva, Goulias, \& Dalal, 2012). Other studies have dealt with the self-selection issue through attitude surveys that measured respondents' preference toward the built environment and travel. These studies found that individual attitudes explain most of the variation in travel patterns (Bagley \& Mokhtarian, 2002; Kitamura, Mokhtarian, \& Laidet, 1997; Schwanen \& Mokhtarian, 2007; Van Acker, Mokhtarian, \& Witlox, 2014). However, the effects of land use on travel while controlling for self-selection are still inconclusive.

Though most existing studies have presented city- or region-wide impacts of land use on travel, recent studies have found a possible nonlinear relationship between land use and travel, which implies the existence of a threshold effect indicating that additional land-use intensification efforts do not work properly at a certain level of intensity (Choi, 2018; Choi \& Zhang, 2017; Hong, 2017). Hong (2017) utilized quadratic regressions to examine the nonlinear influence of population and employment density on automobile use. He found that the effect of density on vehicle travel as well as transportation emissions becomes insignificant as population density reaches a certain level. Choi (2018) applied piecewise regressions to analyze the effects of diverse built environment factors on household VMT and compared four subgroups of neighborhoods by location within the city. He found that one policy does not fit all parts of the city because of variations in the initial development intensity. For instance, though promoting density may be the best intensification effort in the inner city, densification and job creation in outer neighborhoods will be expected to reduce household VMT significantly, and providing more public transit services in newer communities outside the city core seems to be the most influential policy to reduce household VMT.

To explore the effectiveness of several policies implemented simultaneously, some studies have focused on the synergistic or combined effects of land-use policies with other policies such as parking and road pricing/tolls, fuel prices, and public transport policies (Ewing, Hamidi, Gallivan, Nelson, \& Grace, 2013; Rodier, Haydu, Linesch, Alemi, \& Circella, 2014). Rodier et al. (2014) simulated the travel effects of travel demand management policies (e.g., land use, pricing, and transit) in various combinations for five regions in the state of California. They found that the synergistic effects of combined policies are not additive and showed that the interactions can be both positive and negative. Ewing et al. (2013) tested diverse factors, including the built environment, highway capacity, fuel prices, and transit service. They provided a nationally comprehensive assessment using data from 271 different urbanized areas and found that demographics, development patterns, system capacities, and transportation costs influence VMT. Their results showed that increased transit service (coverage and frequency) and lower transit fare levels lead to lower VMT per capita, whereas freeway capacity has a significant and positive impact on VMT per capita. Fuel price and urbanized area density are negatively related to VMT per capita.

Although some studies have focused on the threshold and interaction effects of land use on travel, few have paid attention to interactions among land-use policies with a focus on threshold effects. This study fills this gap and enriches the literature by examining how different land-use factors interact with each other at different levels of development intensity. 


\section{Study area}

To explore this issue further, we used data from the Austin metropolitan statistical area (MSA) located in central Texas, which consists of five counties: Travis, Williamson, Hays, Bastrop, and Caldwell (Figure 1). This fast-growing MSA nearly tripled in size over three decades (growing from 585,000 people in 1980 to 1.71 million in $2010^{1}$ ) thanks to its lower cost of living compared with the East and West coasts as well as its bustling job market. However, most of this growth took the form of low-density residential development across the suburban fringe of Travis, Williamson, and Hays counties (CAMPO, 2010).

For a few decades, like other metro areas, central Texas attempted to build enough roadway capacity to meet increased travel demand but was unable to fully accommodate regional travel demand through roadway expansion. It was not until 2010 that Capital Metro, the regional public transportation authority in Austin, expanded its fixed route bus service to include commuter rail (MetroRail service was first launched to connect Downtown Austin with northern suburbs). After that, the first bus rapid transit (BRT) route, MetroRapid, was launched in January 2014. Two rapid routes are currently operating, with more planned for expansion in the coming years.

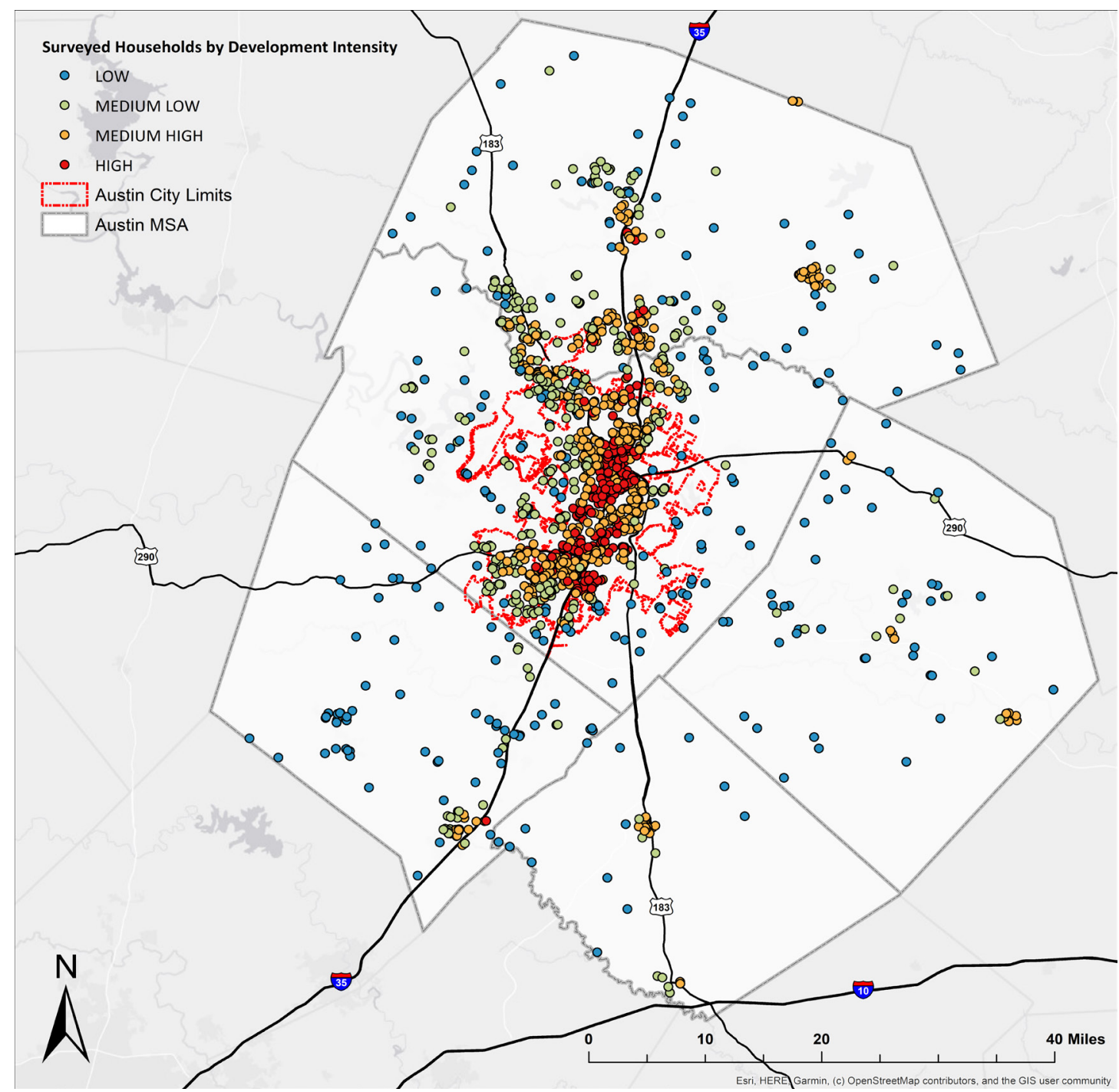

Figure 1. Study area and households 


\section{$4 \quad$ Research data and method}

The primary data source for this study is the 2006 Austin Travel Survey (ATS), which is a part of a series of comprehensive travel surveys conducted by the CAMPO. As shown in Figure 1, approximately 50\% of households (700 out of 1,331 households in the sample) are located within the Austin city limits, whereas the rest of the surveyed households (631 households) are located across the five counties that make up the MSA. This dataset includes detailed information about the surveyed individuals' trips and activities as well as information about the demographic and socioeconomic characteristics of surveyed individuals/households and vehicles they own. The following section discusses the categories and variables used to explore threshold and interaction effects using the detailed 2006 ATS household data.

\subsection{Household and travel variables}

An extensive body of literature supports the influence of socioeconomic characteristics and the built environment on travel outcomes (Ewing \& Cervero, 2001). In this study, we derived four commonly specified variables for household socioeconomic characteristics from the 2006 ATS survey to explain vehicle travel: household size, vehicle availability, household income, and worker count.

The survey respondents reported their daily trip logs, including travel time and distance. To reduce inaccuracies of reported trip distance by the surveyed travelers, the network distance for each trip was estimated based on the assumption of the shortest path using TransCAD GIS. During the cleaning process, trips without trip length information were eliminated. As a result of the process, 13,155 trips were included in this study. For the analysis, trip lengths were aggregated into the household level.

\subsection{Land-use variables: Density, diversity, and design}

We tested three land-use policies and examined their effects on household vehicle travel using three built environment characteristics of the surrounding neighborhoods. To derive land-use variables, we first created one-mile network buffers from individual households with an assumption that it takes 20 minutes for an average person to walk for one mile. Using the ArcGIS software with demographic data from the U.S. Census Bureau and spatial data from local and regional agencies, we derived three land-use variables representing density, diversity, and design (3D variables) (Cervero \& Kockelman, 1997). These land-use variables reflected land-use density, the level of mixed-use development, and street connectivity, respectively. In addition to the three D-variables, we considered a transit variable to mainly control the effect of transit service on household VMT. We derived the transit variable by computing the total number of operating miles of buses passing through individual buffers.

Table 1 provides the formulas and descriptions for the three D-variables measured in the study. To measure the density feature more accurately, we used the prorated sum of the population for the 2000 census block groups that intersected with the buffer. Considering only lots designated as single- or multi-family residential, we first calculated the population density for individual census block groups. Then, we multiplied the density by the amount of residential acreage within the block group contributing to the buffer and summed the populations of all block groups intersecting the individual buffer areas. Using the prorated population, we re-estimated population density per residential square mile for the buffer. For the diversity index, we calculated an entropy score as proposed in Cervero and Kockelman (1997) using the five land-use categories, including single family, multi family, commercial, industrial, and institutional (public). The design variable was calculated as the density of the number of 
intersections with at least four ways per square mile of gross land area within the buffer. These variables have all been commonly used in research on the three D-variables and travel behavior, yet we fully recognize that these measures clearly do not represent all dimensions of what are in several cases complex constructs (Ewing \& Cervero, 2010).

Table 1. 3D measurement

\begin{tabular}{lll}
\hline D-variables & Measurement & Description \\
\hline Density & $\frac{\text { Prorated sum of population }}{\text { Residential land area in the buffer }}$ Population per acre \\
\cline { 2 - 2 } Diversity & $\frac{-\left[\sum_{i=1}^{n} P_{i} \times \ln P_{i}\right]}{\ln (n)}$ Land-use mix (entropy) \\
Design & $\frac{\text { Number of } 4 \text { or more way intersections }}{\text { Gross land area in the buffer }}$ 4+ way intersection per square mile \\
\hline
\end{tabular}

\subsection{Development intensity and interaction terms}

To examine threshold effects, we explored subgroups by development intensity, which was determined based on the three built environment characteristics. We first formed four subgroups for each built environment characteristic (i.e., 25\% of households according to density, diversity, and design). Then, we assigned one to four points to these subgroups depending on the level of each land-use factor. For instance, low density, diversity, and design were assigned a score of one, whereas high density, diversity, and design were assigned a score of four. Finally, we created a composite factor that summed up the points for all three land-use features to determine the level of overall development intensity of a given area (Figure 2).
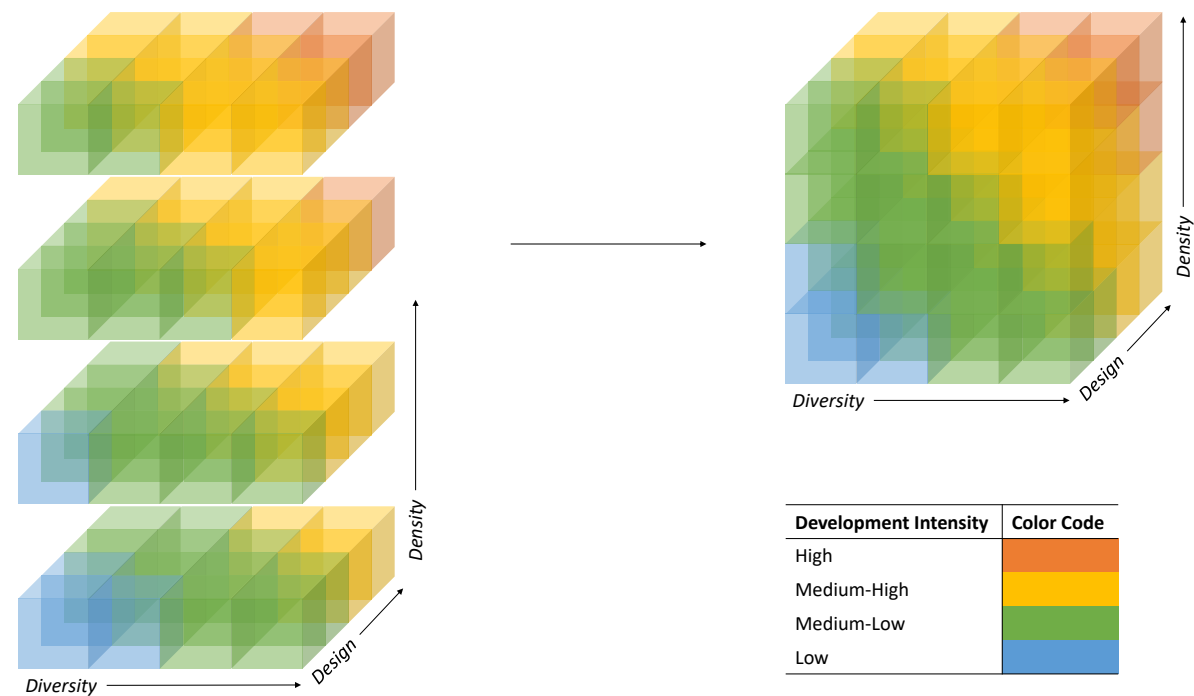

Figure 2. Development intensity classification

Figure 1 also shows the distribution of households by the level of development intensity. House- 
holds along major roadways (Texas State Highway Loop 1, I-35, U.S. Route 290, US-183) within city limits tend to live in neighborhoods that are considered high-development areas, whereas households living farther away from the city limits tend to live in less developed neighborhoods.

The initial analysis with continuous variables where we simply explored interaction effects by multiplying interactive terms was not significant, so we next explored subgroups by development intensity. We created interaction terms by multiplying a dummy-coded development intensity and three land-use factors. We utilized the interaction variables to test whether interaction effects existed as well as whether the influence had a certain threshold or not.

\section{$5 \quad$ Results}

Table 2a shows the descriptive statistics of the entire sample. The sampled households, on average, drove 42 miles per travel day. The average household size and number of vehicles were 2.84 and 1.93 , respectively. Average household income was approximately $\$ 56,500$, and on average, a household had 1.2 workers. Finally, the means of population density, land-use mix entropy, and 4+ way intersection density were 5.46 (residents/acre), 0.58, and 30.1 (4+ way intersections $/ \mathrm{mi}^{2}$ ), respectively. On average, households living in the Austin MSA can travel by bus approximately 100 miles from the bus stops within the one-mile buffer.

Table 2. Descriptive statistics

a. Entire sample

\begin{tabular}{|c|c|c|c|c|c|}
\hline \multirow[t]{2}{*}{ Variable } & \multirow[t]{2}{*}{ Description } & \multicolumn{4}{|c|}{ Entire Sample } \\
\hline & & Min. & Max. & Mean & Std. Dev. \\
\hline VMT & Household daily VMT & 0 & 321.62 & 42.05 & 37.02 \\
\hline SIZE & Household size & 1 & 13 & 2.84 & 1.54 \\
\hline VEHICLE & Household vehicle count & 0 & 7 & 1.93 & 0.90 \\
\hline INCOME & Household income in $\$ 1000$ & 2.5 & 200 & 56.47 & 44.80 \\
\hline WORKER & Household worker count & 0 & 6 & 1.21 & 0.92 \\
\hline DENSITY & Population density (acre) & 0 & 22.25 & 5.46 & 3.97 \\
\hline DIVERSITY & Land-use mix (entropy) & 0.02 & 0.86 & 0.58 & 0.15 \\
\hline DESIGN & $4+$ way intersection density $\left(\mathrm{mi}^{2}\right)$ & 0 & 196.10 & 30.05 & 25.56 \\
\hline TRANSIT & Total number of miles of bus routes passing through buffer (mi) & 0 & $1,181.70$ & 106.20 & 171.60 \\
\hline
\end{tabular}

b. Subgroups by development intensity

\begin{tabular}{|c|c|c|c|c|c|c|c|c|c|c|c|c|}
\hline \multirow[t]{2}{*}{ Variable } & \multicolumn{3}{|c|}{$\begin{array}{l}\text { Low intensity } \\
\qquad(\mathrm{n}=271)\end{array}$} & \multicolumn{3}{|c|}{$\begin{array}{l}\text { Medium-low intensity } \\
\qquad(\mathrm{n}=345)\end{array}$} & \multicolumn{3}{|c|}{$\begin{array}{l}\text { Medium-high intensity } \\
\qquad(\mathrm{n}=505)\end{array}$} & \multicolumn{3}{|c|}{$\begin{array}{l}\text { High intensity } \\
\qquad(\mathrm{n}=210)\end{array}$} \\
\hline & Min & Max & Mean & Min & Max & Mean & Min & Max & Mean & Min & Max & Mean \\
\hline VMT & 0.02 & 321.62 & 63.48 & 0 & 180.87 & 45.70 & 0 & 230.99 & 34.94 & 0 & 168.91 & 25.48 \\
\hline SIZE & 1 & 13 & 3.03 & 1 & 9 & 3.09 & 1 & 8 & 2.67 & 1 & 10 & 2.60 \\
\hline VEHICLE & 0 & 7 & 2.15 & 0 & 6 & 2.10 & 0 & 6 & 1.79 & 0 & 4 & 1.69 \\
\hline INCOME & 2.50 & 200 & 58.51 & 2.50 & 200 & 67.79 & 2.50 & 200 & 53.94 & 2.50 & 200 & 41.31 \\
\hline WORKER & 0 & 6 & 1.27 & 0 & 4 & 1.28 & 0 & 4 & 1.15 & 0 & 4 & 1.12 \\
\hline DENSITY & 0 & 4.94 & 1.20 & 0.19 & 11.36 & 3.69 & 1.17 & 22.25 & 6.78 & 5.11 & 21.18 & 10.67 \\
\hline DIVERSITY & 0.02 & 0.61 & 0.38 & 0.21 & 0.81 & 0.54 & 0.40 & 0.86 & 0.66 & 0.62 & 0.80 & 0.70 \\
\hline DESIGN & 0 & 24.57 & 5.43 & 0 & 113.87 & 19.99 & 2.87 & 137.26 & 38.54 & 26.16 & 196.10 & 57.96 \\
\hline TRANSIT & 0 & 73.70 & 2.84 & 0 & 323.7 & 32.38 & 0 & $1,181.7$ & 127.12 & 0 & $1,141.1$ & 310.54 \\
\hline
\end{tabular}


The level of household VMT as well as other characteristics varied by subgroup. Households tend to drive less as the development intensity of a given area increases. For example, households living in a high-development-intensity neighborhood on average drive 38 miles less than those living in a lowdevelopment-intensity neighborhood. The three land-use features seem to be correlated. In other words, if a neighborhood is dense, that neighborhood is likely to be mixed with other functions of land use and well connected by road networks with more transit service available. Household characteristics also seem to be related to the neighborhood development intensity. Household size and vehicle ownership decrease as an area is developed. In terms of household income, a household living in a medium-low level of development intensity tends to earn more money than households in the other subgroups. This could be partly related to the number of household workers.

We ran a series of regression models with diverse household characteristics, land-use factors, and interaction terms to examine the threshold and interaction effects on log-transformed household daily VMT. The results are shown in Table 3.

Table 3. Regression results of log transformed household daily VMT

\begin{tabular}{|c|c|c|c|c|c|c|c|c|c|c|c|c|}
\hline \multirow[t]{2}{*}{$\mathrm{DV}=\mathrm{LN}(1+\mathrm{VMT})$} & \multicolumn{3}{|c|}{ Model 1} & \multicolumn{3}{|c|}{ Model 2} & \multicolumn{3}{|c|}{ Model 3} & \multicolumn{3}{|c|}{ Model 4} \\
\hline & B & S.E. & sig. & B & S.E. & sig. & B & S.E. & sig. & B & S.E. & sig. \\
\hline \multicolumn{13}{|c|}{ Household Characteristics } \\
\hline SIZE & $0.060^{\mathrm{a}}$ & 0.018 & 0.001 & $0.060^{\mathrm{a}}$ & 0.018 & 0.001 & $0.062^{\mathrm{a}}$ & 0.018 & 0.000 & $0.063^{\mathrm{a}}$ & 0.018 & 0.000 \\
\hline VEHICLE & $0.224^{\mathrm{a}}$ & 0.031 & 0.000 & $0.223^{\mathrm{a}}$ & 0.031 & 0.000 & $0.216^{a}$ & 0.031 & 0.000 & $0.218^{\mathrm{a}}$ & 0.031 & 0.000 \\
\hline INCOME & $0.003^{\mathrm{a}}$ & 0.001 & 0.000 & $0.003^{\mathrm{a}}$ & 0.001 & 0.000 & $0.003^{\mathrm{a}}$ & 0.001 & 0.000 & $0.003^{\mathrm{a}}$ & 0.001 & 0.000 \\
\hline WORKER & $0.251^{\mathrm{a}}$ & 0.031 & 0.000 & $0.249^{\mathrm{a}}$ & 0.031 & 0.000 & $0.258^{\mathrm{a}}$ & 0.031 & 0.000 & $0.257^{\mathrm{a}}$ & 0.031 & 0.000 \\
\hline \multicolumn{13}{|c|}{ Land-use Characteristics } \\
\hline DENSITY (DEN) & $-0.021^{\mathrm{a}}$ & 0.008 & 0.005 & & & & & & & & & \\
\hline DIVERSITY (DIV) & -0.260 & 0.196 & 0.184 & & & & & & & & & \\
\hline DESIGN (DES) & -0.002 & 0.001 & 0.055 & & & & & & & & & \\
\hline TRANSIT & $-0.001^{a}$ & 0.000 & 0.000 & $-0.001^{a}$ & 0.000 & 0.000 & $-0.001^{\mathrm{a}}$ & 0.000 & 0.000 & $-0.001^{\mathrm{a}}$ & 0.000 & 0.000 \\
\hline \multicolumn{13}{|l|}{ Development Intensity } \\
\hline \multicolumn{13}{|l|}{ Low (LOW) (ref.) } \\
\hline Medium-low (ML) & & & & $-0.292^{a}$ & 0.069 & 0.000 & & & & & & \\
\hline Medium-high (MH) & & & & $-0.371^{a}$ & 0.068 & 0.000 & & & & & & \\
\hline High (HIGH) & & & & $-0.436^{\mathrm{a}}$ & 0.094 & 0.000 & & & & & & \\
\hline \multicolumn{13}{|c|}{ Development Intensity $\times$ DENSITY } \\
\hline $\mathrm{LOW} \times \mathrm{DEN}$ & & & & & & & 0.005 & 0.047 & 0.911 & & & \\
\hline $\mathrm{ML} \times \mathrm{DEN}$ & & & & & & & $-0.045^{b}$ & 0.021 & 0.030 & & & \\
\hline $\mathrm{MH} \times \mathrm{DEN}$ & & & & & & & -0.012 & 0.013 & 0.359 & & & \\
\hline $\mathrm{HIGH} \times \mathrm{DEN}$ & & & & & & & 0.010 & 0.018 & 0.569 & & & \\
\hline \multicolumn{13}{|c|}{ Development Intensity $\times$ DIVERSITY } \\
\hline LOW $\times$ DIV & & & & & & & 0.380 & 0.345 & 0.272 & & & \\
\hline $\mathrm{ML} \times \mathrm{DIV}$ & & & & & & & 0.013 & 0.258 & 0.960 & & & \\
\hline $\mathrm{MH} \times \mathrm{DIV}$ & & & & & & & -0.288 & 0.242 & 0.233 & & & \\
\hline $\mathrm{HIGH} \times \mathrm{DIV}$ & & & & & & & -0.749 & 0.421 & 0.075 & & & \\
\hline \multicolumn{13}{|c|}{ Development Intensity $\times$ DESIGN } \\
\hline LOW $\times$ DES & & & & & & & -0.016 & 0.009 & 0.067 & & & \\
\hline ML×DES & & & & & & & -0.003 & 0.003 & 0.402 & & & \\
\hline $\mathrm{MH} \times \mathrm{DES}$ & & & & & & & -0.001 & 0.002 & 0.718 & & & \\
\hline $\mathrm{HIGH} \times \mathrm{DES}$ & & & & & & & 0.001 & 0.003 & 0.776 & & & \\
\hline
\end{tabular}




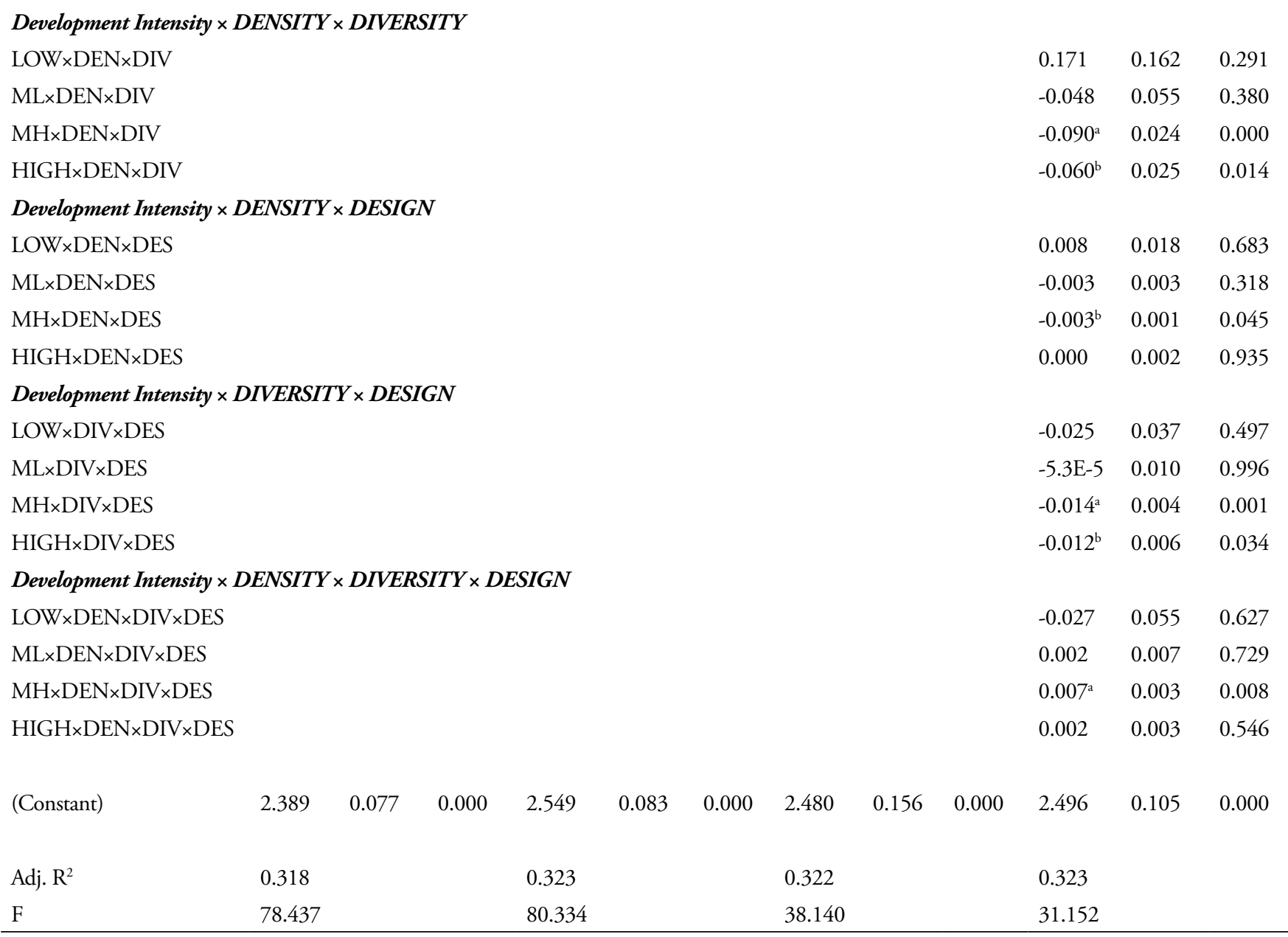

a significant at 0.01 level; ${ }^{\text {b }}$ significant at 0.05 level

As expected, four household characteristics were significant and strong predictors of household daily VMT. Among them, vehicle ownership and the number of workers influenced household vehicle travel the most. The land-use-only model suggests that all three land-use and transit factors have significant impacts on reducing vehicle travel (not shown). However, when household characteristics and land-use variables were regressed together on log-transformed household daily VMT, the effects of diversity and design features became insignificant (model 1). The insignificance of the diversity and design features was partly because the effect of density might absorb the effects of the land-use mix and street network improvement. Another explanation could be that the addition of land uses to an area that already meets the travel preferences of the residents (i.e., residential self-selection) would have no additional significant benefits in terms of reducing driving (Stevens, 2017). In line with the initial expectations, as more transit service becomes available, households are likely to drive less.

In model 2, with low development intensity as a reference, household characteristics and the levels of development intensity were regressed on household VMT. The coefficients of each development intensity indicated the difference in household daily VMT in percentage compared to low-development households. For example, the coefficient of medium-low development intensity $(-0.292)$ suggested that a household living in a neighborhood with a medium-low level of development intensity is likely to drive $30 \%$ less than households with a low-development intensity with all other household characteristics being equal. 
To examine the threshold effects of each land-use policy according to development intensity, we introduced the interaction terms of development intensity and individual land-use factors to model 3. The model produced an interesting outcome. Only the density feature with medium-low development intensity was significant. The outcome suggests that densification effort alone may not work properly in either very low- or high-development areas. In very low-development areas, private automobiles are still a better option to move around, partly because of favorable design for motorists and homogenous land use within the areas. In contrast, the same effort in high-development areas may push travelers out of their neighborhood partly because of a high volume of traffic in the area or a jobs and housing mismatch. The outcome also shows that a single effort, particularly mixed-use development or street network improvement, will not seem to have a significant impact on reducing household vehicle travel across all levels of development intensity. This suggests that a densification effort should be employed first. However, a further investigation is needed.

Model 4 tested the interaction effects as well as threshold effects of land-use policies. We found three interesting results. First, the interaction effects of land-use policies seemed to be significant in areas with a relatively higher development intensity. Second, even though the diversity or design feature alone did not seem to be a significant factor to reduce household vehicle travel in this case, the interaction of diversity and design features (with density or together) seemed to work properly. Last, the interaction term of all three land-use policies was not significant except for the medium-high development intensity. However, the direction of the effect differed from our expectation. The first and second findings can be supported by the idea that land-use strategies can produce synergistic effects with other land-use policies even better when a given area is developed to a certain degree. Another explanation can be suggested for the second finding. It is highly likely that each land-use feature intensifies other land-use features in this case. However, too much land-use intensification effort may work in an undesirable way because those who still have a strong preference for driving may drive farther if they can easily park. In addition, they may oppose new developments near their residence and feel uncomfortable with those intensive land uses.

\section{Discussion and conclusion}

The analysis in this study neither addresses all interactive effects in the 7D literature (Ewing et al., 2015) nor fully evaluates the continuous nature of development intensity. It does, however, advance the state of research by demonstrating that threshold and interaction effects merit further consideration in the 7D travel behavior literature (Choi, 2018; Hong, 2017). By introducing thresholds and interaction terms, the analysis provides a realistic outcome of land-use policies that are implemented on the ground.

As an exploratory study, the analysis has limitations that can be addressed in future investigations. In this study, we use just one possible approach to operationalize metropolitan land-use intensity to create categories where threshold level effects may be found. Alternative specifications can and should be considered in future research. Another improvement would be the introduction of other groups of influences on travel behavior such as destination accessibility, transit service quality/frequency, fuel price, and attitudinal factors (Johnston \& Rodier, 1999; Levinson, 1998; Van Acker, Van Wee, \& Witlox, 2010). In all cases, we rely on single measures for what in many ways are complex phenomena, such as street design influences on travel behavior. Considerable work remains to be done in creating more nuanced composite measures of these complex $7 \mathrm{D}$ variables than has been completed to date. It is also a single study in a single metropolitan area; it would be useful to extend this analysis to a national dataset with more variation in the $7 \mathrm{D}$ variables. Lastly, travel behavior using other modes of transportation needs to be investigated. 
Despite the limitations, the analysis with interactions and thresholds has led to several important findings: at least in the Austin context, land-use intensification efforts (densification, mixed-use development, street network improvement) produce a desired outcome only if they are implemented with other land-use strategies in areas with a relatively higher-intensity. Mixed-use development or street network improvement alone may not have a significant impact on reducing vehicle travel, but given the correlation with density and design features, it can accompany other land-use intensifications whose effects can vary by the level of development intensity.

This study also shows that an optimal level of development intensity might exist, which calls for further investigation. From the modelling perspective, this research suggests the importance of the exploration of threshold and interaction effects to provide a more nuanced understanding of the best use of other D-variables to reduce VMT in urbanizing areas.

\section{Acknowledgements}

This research was supported in part by Oak Foundation through the Richard Parker Professorship in Metropolitan Growth and Change.

\section{Data availability}

The data for this paper is available by request. 


\section{References}

Bagley, M. N., \& Mokhtarian, P. L. (2002). The impact of residential neighborhood type on travel behavior: A structural equations modeling approach. The Annals of Regional Science, 36(2), 279-297. https://doi.org/10.1007/s001680200083

Bauman, A. E., Reis, R. S., Sallis, J. F., Wells, J. C., Loos, R. J. F., Martin, B. W., \& Lancet Physical Activity Series Working Group. (2012). Correlates of physical activity: Why are some people physically active and others not? The Lancet, 380(9838), 258-271. https://doi.org/10.1016/S01406736(12)60735-1

Bhat, C. R., Astroza, S., Sidharthan, R., Alam, M. J. B., \& Khushefati, W. H. (2014). A joint countcontinuous model of travel behavior with selection based on a multinomial probit residential density choice model. Transportation Research Part B: Methodological, 68, 31-51. https://doi.org/10.1016/j. trb.2014.05.004

Bhat, C. R., \& Guo, J. Y. (2007). A comprehensive analysis of built environment characteristics on household residential choice and auto ownership levels. Transportation Research Part B: Methodological, 41(5), 506-526. https://doi.org/10.1016/j.trb.2005.12.005

Boarnet, M. G., \& Crane, R. (2001). Travel by design: The influence of urban form on travel. Oxford, UK: Oxford University Press.

Brownstone, D., \& Golob, T. F. (2009). The impact of residential density on vehicle usage and energy consumption. Journal of Urban Economics, 65(1), 91-98. https://doi.org/10.1016/j.jue.2008.09.002

CAMPO. (2010). CAMPO 2035 regional transportation plan appendices. Retrieved from www.campotexas.org

Cao, X., Mokhtarian, P. L., \& Handy, S. L. (2009). Examining the impacts of residential self-selection on travel behaviour: A focus on empirical findings. Transport Reviews, 29(3), 359-395. https://doi. org/10.1080/01441640802539195

Cervero, R. (2002). Built environments and mode choice: Toward a normative framework. Transportation Research Part D: Transport and Environment, 7(4), 265-284. https://doi.org/10.1016/S13619209(01)00024-4

Cervero, R., \& Kockelman, K. (1997). Travel demand and the 3Ds: Density, diversity, and design. Transportation Research Part D: Transport and Environment, 2(3), 199-219. https://doi.org/10.1016/ S1361-9209(97)00009-6

Choi, K. (2018). The influence of the built environment on household vehicle travel by the urban typology in Calgary, Canada. Cities, 75, 101-110. https://doi.org/10.1016/j.cities.2018.01.006

Choi, K., \& Zhang, M. (2017). The net effects of the built environment on household vehicle emissions: A case study of Austin, TX. Transportation Research Part D: Transport and Environment, 50, 254-268. https://doi.org/10.1016/j.trd.2016.10.036

de Abreu E Silva, J., Goulias, K. G., \& Dalal, P. (2012). Structural equations model of use patterns, location choice, and travel behavior in Southern California. Transportation Research Record: Journal of the Transportation Research Board, 2323(1), 35-45. https://doi.org/10.3141/2323-05

Ewing, R., \& Cervero, R. (2001). Travel and the built environment: A synthesis. Transportation Research Record: Journal of the Transportation Research Board, 1780(1), 87-114. https://doi. org/10.3141/1780-10

Ewing, R., \& Cervero, R. (2010). Travel and the built environment: A meta-analysis. Journal of the American Planning Association, 76(3), 265-294. https://doi.org/10.1080/01944361003766766

Ewing, R., Hamidi, S., Gallivan, F., Nelson, A. C., \& Grace, J. B. (2013). Combined effects of compact development, transportation investments, and road user pricing on vehicle miles traveled in urbanized areas. Transportation Research Record: Journal of the Transportation Research Board, 2397(1), 117-124. https://doi.org/10.3141/2397-14 
Ewing, R., Hamidi, S., Gallivan, F., Nelson, A. C., \& Grace, J. B. (2014). Structural equation models of VMT growth in US urbanized areas. Urban Studies, 51(14), 3079-3096. https://doi. org/10.1177/0042098013516521

Ewing, R., Tian, G., Goates, J., Zhang, M., Greenwald, M. J., Joyce, A., ... Greene, W. (2015). Varying influences of the built environment on household travel in 15 diverse regions of the United States. Urban Studies, 52(13), 2330-2348. https://doi.org/10.1177/0042098014560991

Hong, J. (2017). Non-linear influences of the built environment on transportation emissions: Focusing on densities. Journal of Transport and Land Use, 10(1), 229-240. https://doi.org/http://dx.doi. org/10.5198/jtlu.2015.815

Johnston, R. A., \& Rodier, C. J. (1999). Synergisms among land use, transit, and travel pricing policies. Transportation Research Record, 1670(1), 3-7. https://doi.org/10.3141/1670-01

Kenworthy, J. (2006). The eco-city: Ten key transport and planning dimensions for sustainable. Environment \& Urbanization, 18(1), 67-85. https://doi.org/10.1177/0956247806063947

Kitamura, R., Mokhtarian, P. L., \& Laidet, L. (1997). A micro-analysis of land use and travel in five neighborhoods in the San Francisco Bay Area. Transportation, 24(2), 125-158. https://doi. org/10.1023/A:1017959825565

Levinson, D. M. (1998). Accessibility and the journey to work. Journal of Transport Geography, 6(1), $11-21$.

Mokhtarian, P. L., \& Cao, X. (2008). Examining the impacts of residential self-selection on travel behavior: A focus on methodologies. Transportation Research Part B: Methodological, 42(3), 204-228. https://doi.org/10.1016/j.trb.2007.07.006

Pinjari, A. R., Pendyala, R. M., Bhat, C. R., \& Waddell, P. A. (2011). Modeling the choice continuum: An integrated model of residential location, auto ownership, bicycle ownership, and commute tour mode choice decisions. Transportation, 38(6), 933-958. https://doi.org/10.1007/s11116-011-9360-y

Rawlins, R., \& Paterson, R. (2009). Sustainable buildings and communities: Climate change and the case for federal standards. Cornell Journal of Law and Policy, 19, 335.

Rodier, C., Haydu, B., Linesch, N. J., Alemi, F., \& Circella, G. (2014). Synergistic effects of transit, land use, and vehicle pricing policies on vehicle travel and greenhouse gas emissions. Presented at Transportation Research Board 93rd Annual Meeting, Washington, DC.

Schwanen, T., \& Mokhtarian, P. L. (2007). Attitudes toward travel and land use and choice of residential neighborhood type: Evidence from the San Francisco Bay Area. Housing Policy Debate, 18(1), 171-207. https://doi.org/10.1080/10511482.2007.9521598

Stevens, M. R. (2017). Does compact development make people drive less? Journal of the American Planning Association, 83(1), 7-18. https://doi.org/10.1080/01944363.2016.1240044

Van Acker, V., Mokhtarian, P. L., \& Witlox, F. (2014). Car availability explained by the structural relationships between lifestyles, residential location, and underlying residential and travel attitudes. Transport Policy, 35, 88-99. https://doi.org/10.1016/j.tranpol.2014.05.006

Van Acker, V., Van Wee, B., \& Witlox, F. (2010). When transport geography meets social psychology: Toward a conceptual model of travel behaviour. Transport Reviews, 30(2), 219-240. https://doi. org/10.1080/01441640902943453

Van Wee, B. (2009). Self-selection: A key to a better understanding of location choices, travel behaviour and transport externalities? Transport Reviews, 29(3), 279-292. https://doi. org/10.1080/01441640902752961

Wang, K. (2013). Causality between built environment and travel behavior. Transportation Research Record, 2397(1), 80-88. https://doi.org/10.3141/2397-10

Zhang, M. (2004). The role of land use in travel mode choice: Evidence from Boston and Hong Kong. Journal of the American Planning Association, 70(3), 344-360. https://doi. org/10.1080/01944360408976383 